\title{
To the 70th Anniversary of the Journal Vestnik Moskovskogo Universiteta. News from Biologists
}

\author{
G. V. Morgunova, A. N. Khokhlov*, and M. P. Kirpichnikov \\ School of Biology, Moscow State University, Moscow, 119234 Russia \\ *e-mail:khokhlov@mail.bio.msu.ru \\ Received December 10, 2015
}

DOI: $10.3103 / \mathrm{S} 0096392516110018$

On September 2016, Vestnik Moskovskogo Universiteta (Herald of Moscow University) marks 70 years from date of publication of its first issue. Our edition is rightfully considered to be one of the oldest college scientific journals in Russia. Today, Vestnik Moskovskogo Universiteta is represented by 27 individual journals (Series), among which is Vestnik Moskovskogo Universiteta, Seriya 16: Biologiya (English-language edition is Moscow University Biological Sciences Bulletin).

The structure of the journal has changed many times throughout its lifetime. Independent series appeared, and their format was changed; later, translated versions were issued. These journals published mainly articles written by our colleagues and graduate students, providing the world scientific community with information about achievements and successes of scientists in the Lomonosov Moscow State University. Recently, however, the situation has begun to change dramatically with the emergence of a huge number of "competitors" (the number of scientific journals has increased many times in a few decades) and the growing importance of global citation systems. Almost all scientific editions are forced to keep up with the times and take into account the demands placed upon them by standards established, in particular, by such giants in the field of scientometric indexing as Scopus and Web of Science. According to global practice, scientific publications that meet specified requirements are mainly taken into account in allocation of research grants. Although this approach cannot be justified completely, it is impossible to ignore this fact now.

In 2014, Vestnik Moskovskogo Universiteta, Seriya 16: Biologiya won the contest for the state support of development programs and promotion of Russian scientific journals into international scientific and information space, organized by the Ministry of Education and Science of the Russian Federation and the National Electronic Information Consortium (NEICON). Outrunning over 500 competitors, the journal became one of two winners in the "Biology" section and received financial support for 3 years. According to the terms of the award, we had to undertake a number of reforms in our edition that are generally in line with the above requirements of global citation systems.

Focusing on these requirements, we have changed a lot in policy and format of the journal. The most important change is that Vestnik Moskovskogo Universiteta, Seriya 16: Biologiya is open today to all scientists, regardless of their place of work. We publish articles from any scientific organization, including foreign institutions. Moreover, the editorial board routinely orders review papers on relevant topics from leading experts, biologists, from not only Russia but also those who work abroad. In this regard, detailed information about affiliations of all authors and contact data is now given on the first page of each article. The same information is duplicated in English-language summary. Format of articles is brought in line with international standards, wherever possible.

To make the editorial board of the journal less "local," we have created the advisory board of Vestnik Moskovskogo Universiteta, Seriya 16: Biologiya which included "external" experts both from Russia and from abroad; among them:

- Vladimir N. Anisimov, Corresponding Member of the Russian Academy of Sciences, Head of the Department of Carcinogenesis and Oncogerontology, N.N. Petrov Research Institute of Oncology, Ministry of Healthcare of the Russian Federation (St. Petersburg);

- Yegor S. Vassetzky, Co-leader of the Nuclear Organization and Disease Models Group, Gustave Roussy Institute of Oncology (Villejuif, France);

- Andrey V. Vasiliev, Director of Koltsov Institute of Developmental Biology, Russian Academy of Sciences (Moscow); 
- Natalya G. Kolosova, Head of the Sector of Molecular Mechanisms of Aging, Institute of Cytology and Genetics, Siberian Branch, Russian Academy of Sciences (Novosibirsk);

- Alexander D. Naumov, Professor of the Department of Radiology and Biophysics, Vitebsk State Academy of Veterinary Medicine (Vitebsk, Belarus);

- Sergei A. Nedospasov, Corresponding Member of the Russian Academy of Sciences, Head of the Laboratory of Molecular Immunology, V.A. Engelhardt Institute of Molecular Biology, Russian Academy of Sciences (Moscow);

- Vasily M. Studitsky, Co-leader of the Laboratory of Cancer Epigenetics, Fox Chase Cancer Center (Philadelphia, United States).

It is expected that the members of the advisory board will be actively involved in the formation of editorial policy, publish periodically their articles and articles of their colleagues in our journal, and assist in reviewing submitted manuscripts.

Several remarks on peer reviews. Recently, we have extended several times the pool of reviewers, by engaging a growing number of experts from other institutions for this work. Having the chance, we would like to thank our colleagues for their invaluable help in the selection, evaluation, and preparation of manuscripts for Vestnik Moskovskogo Universiteta, Seriya 16: Biologiya.

It should be stressed that strict independent blind peer reviewing has enabled us to assess the quality of submitted manuscripts more objectively; it has resulted in a significant increase in the proportion of rejected articles (up to 50-60\%).

From January 1, 2016, we increased the volume of the edition by 1.5 times. We hope that this measure will give the opportunity to shorten the runtime of publication, which, however, even now is only 3-6 months.

We have created a bilingual (Russian/English) website of the journal (http://vestnik-bio-msu. elpub.ru; at the time of writing, the site functions in the test mode) on the Elpub platform of NEICON and with their help, by applying the financial support offered to the journal as a winner of the said contest of the Ministry of Education and Science of the Russian Federation. The site contains, among other things, the section "Electronic Paper Submission," which in the future will offer automatic submission and tracking of manuscripts. There is also information about the journal and the editorial/advisory boards, the requirements for manuscripts, editorial policy, ethics of scientific publications, and others. Publications can be searched by keywords.

In 2015, an electronic archive of Russian-language articles that have been published in Vestnik Moskovskogo Universiteta, Seriya 16: Biologiya for 14 years was finally organized. It is planned to complete, in the near future, the archive with articles from earlier issues, down to 1946.

In 2015, members of the editorial board G.V. Morgunova and A.N. Khokhlov attended the 4th International Scientific and Practical Conference "WorldClass Scientific Publication-2015: Current World Trends and Practice in Editing, Publishing and Assessment of Scientific Publications" (May 26-29, 2015 , St. Petersburg, Russia), as part of our commitment to the grant from the Ministry of Education and Science of the Russian Federation. They gave a presentation entitled "On some alternative approaches to evaluating the effectiveness of scientific journals." In the presentation, a modified method for calculating the article download index was proposed, which enabled, according to the authors, to assess rather adequately the effectiveness of a particular scientific journal. The method was illustrated by the example of the number of downloads in 2009-2013, from Springer website, of English edition articles from 44 Russian scientific journals (mainly biological), including all journals of the series of Moscow University Bulletin. It was demonstrated that the proposed index had quite a weak correlation with the conventional impact factor. The conclusion was that the joint use of both indices in the scientometric analysis of scientific publications is advisable.

As part of the same grant, our journal and NEICON organized a workshop for Moscow State University fellow members and students, dedicated to the current situation with the publication of scientific works; the workshop was held on December 2015 at the School of Biology, Moscow State University. In this workshop, experts warned authors how not to be caught by "parasite journals" and shared how to find the right edition for their scientific publications, prepare an article for submission to a journal, and use electronic resources that are available to employees of the Moscow State University. In particular, the pros and cons of publications in Russian scientific journals were considered in detail. Olga Kirillova, Director of Educational and Consultation Center "School of NEICON," President of the Russian Association of Scientific Editors and Publishers, and Authorized Expert and Consultant of Scopus; Armen Gasparyan, Member of the European Association of Science Editors and the World Association of Medical Editors; Tatiana Kalinina, Head of the Department of Electronic Resources of the Scientific Library of the Moscow State University; and Alexander Khokhlov, Associate Editor-in-Chief of Vestnik Moskovskogo Universiteta, Seriya 16: Biologiya attended the workshop as lecturers.

Today, our journal which consists of two versionsRussian-language Vestnik Moskovskogo Universiteta, Seriya 16: Biologiya and English-language Moscow University Biological Sciences Bulletin-is included in the list of editions recommended by the Higher Attes- 
tation Commission of the Ministry of Education and Science of the Russian Federation and indexed by a number of databases-first of all, Scopus. The edition is also presented in Google Scholar, CAB International, Academic OneFile, CAB Abstracts, Gale, Global Health, Health Reference Center Academic, OCLC, SCImago, Summon by ProQuest, Ulrich's, EBSCO, EastView, and eLIBRARY.RU.

It also should be noted that in 2015, the Russianlanguage version of the journal entered the Russian Sciences Citation Index (RSCI) on the Web of Science platform, so articles published in Vestnik Moskovskogo Universiteta, Seriya 16: Biologiya are now available to users of the best-known system of global citation.

Last year, Scopus and Scimago Journal \& Country Rank updated information in their websites about the English version of our journal indexed by them. It is obvious that almost all of our indicators are steadily growing. According to the data of Scimago Journal \& Country Rank for 2014, Moscow University Biological Sciences Bulletin entered the third quartile within all three of its fields of science, recorded in the system, namely, "Biochemistry, Genetics and Molecular Biology," "Environmental Science," and "Agricultural and Biological Sciences."

Thus, we approach the 70th anniversary with quite significant achievements. However, it is clear that there is a lot more that we need to work on. We would like to invite our colleagues from a variety of research institutions for cooperation as both authors and reviewers or members of the editorial/advisory boards. We also welcome any recommendations aimed at improving Vestnik Moskovskogo Universiteta, Seriya 16: Biologiya and increasing its accessibility to the international scientific community.

Translated by O. Zhukova 